\title{
Correlation between scientific production and democracy
}

Roderic Guigó, roderic.guigo@crg.cat

Center for Genomic Regulation, Universitat Pompeu Fabra

Barcelona, Catalonia.

\section{Abstract}

There is a strong positive correlation between the quality of democracy and the scientific output of countries. The correlation remains even after correcting for research spending.

Scientific progress often occurs through challenging established dogmas and conventions. One could hypothesize, therefore, that societies built on the free exchange of ideas, in which discrepancy is tolerated or even encouraged may be conductive to better research. I computed the correlation between the quality of democracy and the scientific output of countries (see methods, Table S1). The correlation is positive and strong (Spearman correlation $=0.78$, Figure 1 ).

Because there is also a strong correlation between the quality of democracy and research spending (Spearman correlation $=0.75$ ), I used partial correlations to remove the effect of this factor. The correlation between scientific output and quality of democracy remains even after correcting for research spending (Spearman correlation $=0.36, \mathrm{p}-\mathrm{val}<0.005$ ). This could be interpreted as that at similar levels of research funding, stronger democracies appear to produce better science. The deterioration of democracy across the planet (including Europe) is therefore bad news, maybe also for science.

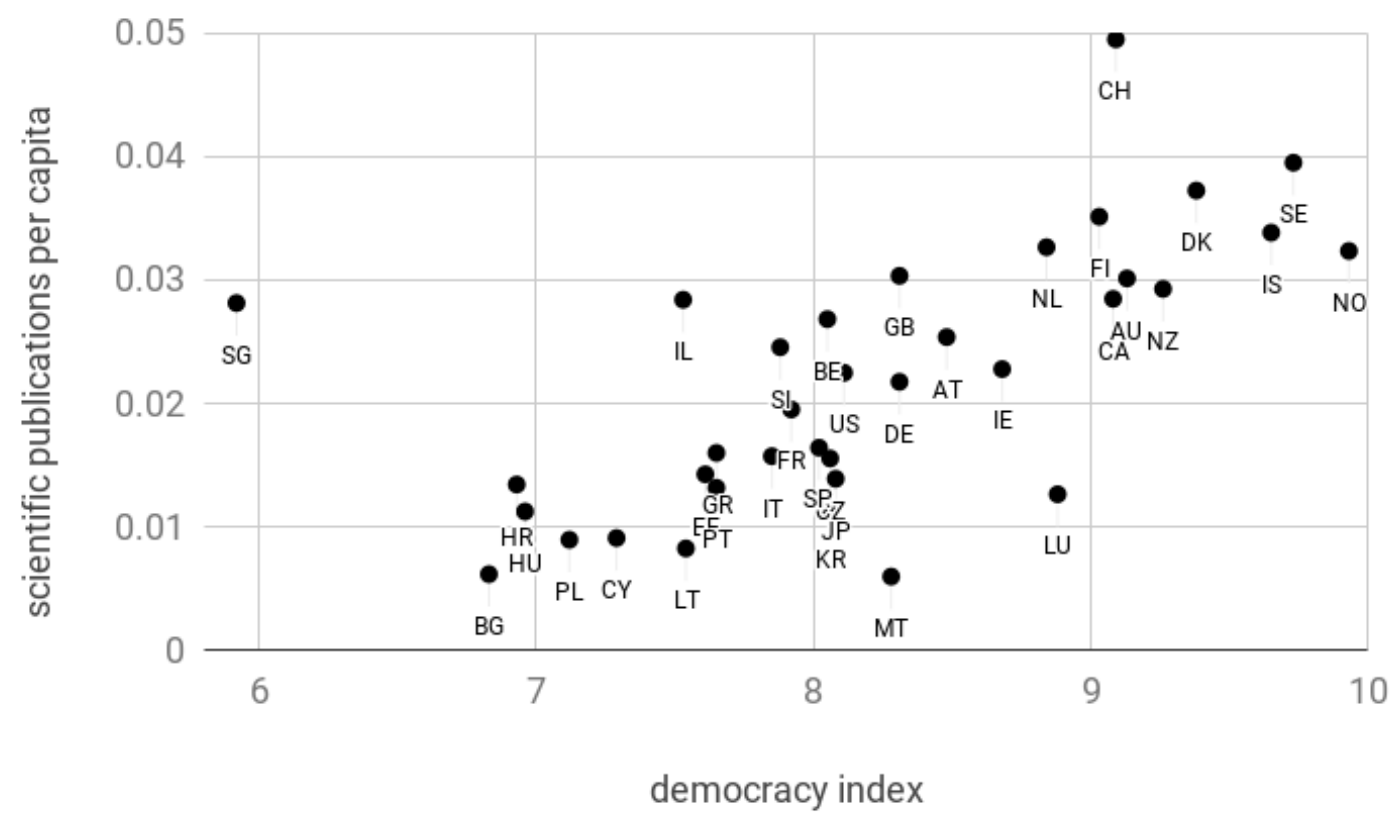

Figure 1. Correlation between the Democracy Index and the number of scientific publications per capita. Only countries with the number of scientific publications per capita larger than 0.005 are plotted. 


\section{Methods}

As a measure of the quality of democracy across countries, I used the overall score of the Democracy Index 2013, published by The Economist Intelligence Unit (1). I obtained the scientific output per capita across countries from (2), which is computed by dividing the number of publications per country, as reported in Scopus by Scimago for the period 1996-2012 (3), by the 2012 population for countries as reported in the Worldbank (4). I used data in the Wikipedia (5) for the research spending per capita by country, which is obtained from a variety of sources, and that corresponds to years 2007 to 2014, depending on the country. All the data is available in Table S1.

I computed the partial correlations using the R ppcor package (6), using the data on Table S1, after striping the country names. The R code used is the following

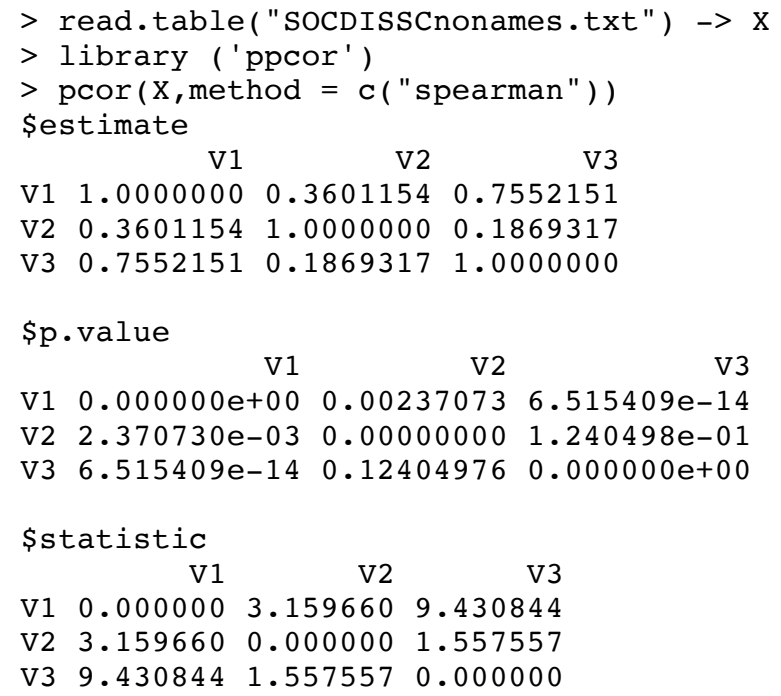

\section{Acknowledgments}

I wrote initially this analysis to be submitted elsewhere in 2014. Calculations should be updated with more recent data.

\section{References}

(1) http://www.eiu.com/public/topical_report.aspx?campaignid=Democracy $\underline{0814}$

(2) http://academia.stackexchange.com/questions/18767/researchpublications-per-capita.

(3) http://www.scimagojr.com/countryrank.php

(4) http://data.worldbank.org/indicator/SP.POP.TOTL

(5) http://en.wikipedia.org/wiki/List_of_countries_by_research_and_develop ment spending

(6) https://cran.r-project.org/web/packages/ppcor/ppcor.pdf 